DOI: $10.31933 / \mathrm{JEMSI}$

Received: 9 Agustus 2020, Revised: 25 September 2020, Publish: 26 Oktober 2020

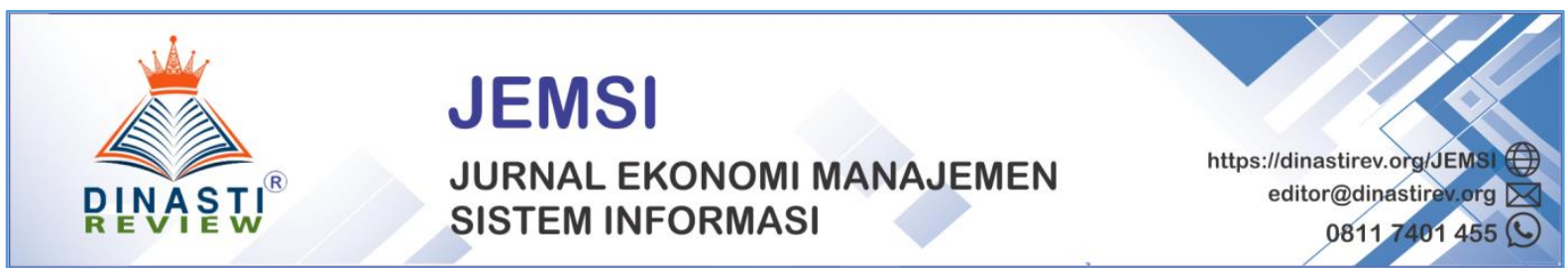

\title{
MODEL PRODUKTIVITAS KERJA ; KOMPENSASI DAN MOTIVASI MELALUI KEPUASAN KERJA SEBAGAI VARIABEL INTERVENING PADA PEGAWAI KANTOR DINAS KESEHATAN SUMATERA BARAT
}

\author{
Robby Dharma ${ }^{1}$, Dori Mittra Candana ${ }^{2}$ \\ ${ }^{1)}$ Universitas Putra Indonesia YPTK Padang, Indonesia, robby_dharma@upiyptk.ac.id \\ ${ }^{2)}$ Universitas Putra Indonesia YPTK Padang, Indonesia, dorimittra@ upiyptk.ac.id
}

\section{Corresponding Author: First Author}

\begin{abstract}
Abstrak: Tujuan penelitian ini untuk mengetahui Pengaruh Kompensasi Dan Motivasi Terhadap Produktivitas Kerja Melalui Kepuasan Kerja Sebagai Variabel Intervening Pegawai Kantor Dinas Kesehatan Sumatera Barat baik secara persial maupun bersama - sama. Sampel dalam penelitian ini mengunakan rumus slovin dengan populasi dan sampel Pegawai pada Dinas Kesehatan Sumatera Barat. Metode analisis data mengunakan analisis regresi berganda dan dengan aplikasi SPSS 21.00. Kompensasi memberikan pengaruh langsung lebih besar dibandingkan pengaruh tidak langsung terhadap Produktivitas Kerja melalui Kepusan kerja sebagai variabel intervening. Dan Motivasi memberikan pengaruh langsung lebih kecil dibandingkan tidak langsung terhadap Produktivitas Kerja melalui Kepusan kerja sebagai variabel intervening. Kontribusi variable Kompensasi Dan Motivasi Terhadap Produktivitas Kerja Melalui Kepuasan Kerja Sebagai Variabel Intervening berpengaruh sebesar 70,6\% sedangkan sisanya dipengaruhi oleh faktor lain diluar penelitian ini.
\end{abstract}

Kata Kunci: Kompensasi, Motivasi, Produktivitas Kerja, Kepuasan Kerja

\section{PENDAHULUAN}

Tujuan pembangunan dinas kesehatan adalah untuk meningkatkan kesadaran, kemauan dan kemampuan hidup sehat bagi setiap orang agar terwujud derajat kesehatan masyarakat yang optimal. Setiap individu berkewajiban ikut serta dalam memelihara dan meningkatkan derajat kesehatan perorangan, keluarga dan masyarakat. Dalam hal itu dinas kesehatan membutuhkan ada nya faktor Sumber Daya Manusia (SDM) yang potensial, Organisasi dituntut menciptakan produktivitas pegawai yang tinggi agar kinerja organisasi dapat dioptimalkan dengan baik, dinas kesehatan harus memiliki pegawai yang termotivasi dan mendapatkan kompensasi yang memadai serta usaha untuk mengelola organisasi seoptimal mungkin sehingga kinerja organisasi meningkat. Berbagai bentuk usaha yang dapat dilakukan untuk pengembangan SDM adalah Bagaimana meningkatkan produktivitas dan kepuasan kerja pegawai dengan memberikan kompensasi dan motvasi kepada pegawai. Pada dinas Kesehatan Sumatera Barat masih ada pegawai yang kurang tepat waktu dalam menyelesaikan tugas dan tingkat kedisiplinannya juga masih kurang, hal itu mengurangi 
produktivitas kerja pada dinas kesehatan Sumatera Barat karena kurang nya motivasi dan kompensasi yang diberikan kepada pegawai. Menurut Gomes (2015:128), produktivitas memiliki dua dimensi, pertama efektivitas yang mengarah kepada pencapaian untuk kerja yang maksimal yaitu pencapaian target yang berkaitan dengan berkualitas, kuantitas, dan waktu, dan yang kedua adalah dimensi efesiensi yang berkaitan dengan upaya membandingkan input dengan realisasi penggunaanya atau bagaimana pekerjaan tersebut dilaksanakan. Untuk mengetahui tingkat produktivitas kerja pegawai pada Dinas Kesehatan Sumatera Barat dapat dilihat pada lampiran absensi pegawai pada tabel 1.1 berikut berikut ini :

Tabel 1.1

Data Absensi Pegawai Kantor Dinas Kesehatan Sumatera Barat tahun 2019

\begin{tabular}{|l|l|l|l|l|l|l|l|l|}
\hline Bulan & $\begin{array}{l}\text { Jumlah } \\
\text { Pegawai }\end{array}$ & Apel & Masuk & Sakit & Izin & $\begin{array}{l}\text { Dinas } \\
\text { Luar }\end{array}$ & $\begin{array}{l}\text { Dinas } \\
\text { Dalam }\end{array}$ & $\begin{array}{l}\text { Tidak } \\
\text { Apel }\end{array}$ \\
\hline Maret & 97 & $\begin{array}{l}81.05 \\
\%\end{array}$ & $69.41 \%$ & $\begin{array}{l}0.98 \\
\%\end{array}$ & $\begin{array}{l}0.49 \\
\%\end{array}$ & $\begin{array}{l}9.72 \\
\%\end{array}$ & $8.51 \%$ & $4.41 \%$ \\
\hline April & 98 & $\begin{array}{l}82.60 \\
\%\end{array}$ & $74.05 \%$ & $\begin{array}{l}2.08 \\
\%\end{array}$ & 0 & $\begin{array}{l}6.55 \\
\%\end{array}$ & $5.19 \%$ & $2.33 \%$ \\
\hline Mei & 98 & $\begin{array}{l}75.86 \\
\%\end{array}$ & $74.13 \%$ & $\begin{array}{l}2.24 \\
\%\end{array}$ & 0 & $\begin{array}{l}5.71 \\
\%\end{array}$ & $\begin{array}{l}15.71 \\
\%\end{array}$ & $6.58 \%$ \\
\hline Juni & 98 & $\begin{array}{l}86.36 \\
\%\end{array}$ & $82.18 \%$ & $\begin{array}{l}1.39 \\
\%\end{array}$ & 0 & $\begin{array}{l}2.04 \\
\%\end{array}$ & $0.12 \%$ & $8.62 \%$ \\
\hline Juli & 103 & $\begin{array}{l}82.87 \\
\%\end{array}$ & $72.46 \%$ & $\begin{array}{l}1.14 \\
\%\end{array}$ & 0 & $\begin{array}{l}4.63 \\
\%\end{array}$ & $\begin{array}{l}17.25 \\
\%\end{array}$ & $5.56 \%$ \\
\hline $\begin{array}{l}\text { Agust } \\
\text { us }\end{array}$ & 103 & $\begin{array}{l}78.22 \\
\%\end{array}$ & $66.80 \%$ & $\begin{array}{l}2.40 \\
\%\end{array}$ & 0 & $\begin{array}{l}8.64 \\
\%\end{array}$ & $\begin{array}{l}17.33 \\
\%\end{array}$ & $4.76 \%$ \\
\hline
\end{tabular}

Sumber:KantorDinas Kesehatan Sumatera Barat

Berdasarkan tabel 1.1 diatas ,dapat terlihat bahwa data absensi pegawai Dinas Kesehatan Sumatera Barat pada tahun 2019 selama 6 (enam) bulan terkhir. Pada bulan Maret dapat dilihat bahwa persentase pegawai yang mengikuti Apel pagi yaitu $81.05 \%$ dan bulan April mengalami peningkatan karena jumlah pegawai yang bekerja pun mengalami peningkatan sehingga persentase pegawai yang mengikuti Apel menjadi 82.60\%, pada bulan Mei mengalami penurunan dibandingkan dengan bulan sebelum nya menjadi $75.36 \%$ Juni kembali mengalami peningkatan $86.36 \%$ Juli dan Agustus karena jumlah pegawainya bertambah persentase pegawai yang mengikutiApel pun meningkat yaitu $82.87 \%$ namun untuk bulan Agustusnya Menurun Dibandingkan dengan Bulan Juli 78.22\%. Naik turunnya persentase pegawai yang mengikuti Apel tersebut dapat dipengaruhi oleh kurangnya motivasi yang diberikan kepada pegawai tentang kedisiplinan kerja, sehingga masih ada pegawai yang malas untuk melakukan Apel.

Selanjutnya pegawai yang masuk bekerja mulai dari bulan Maret $69.41 \%$, bulan April, Mei, Juni karena jumlah pegawainya bertambah dan sama April ke Mei tidak mengalami peningkatan $74.05 \%$ dan $74.13 \%$ pada bulan Juni mengalami peningkatan yaitu 82.18\%. Sedangkan bulan Juli dan Agustus jumlah Pegawainya bertambah sama banyak namun persentase pegawai yang masuk bekerja mengalami penurunan $72.46 \%$ dan $66.80 \%$. Hal tersebut juga bisa disebabkan oleh produktivitas kerja yang menurun akibat pengaruh dari kurangnya kompensasi dan motivasi yang diberikan kepada pegawai yang bekerja,sehingga pegawai kurang bersemangat untuk melakukan pekerjaannya dan malas masuk. 
Tabel berikutnya adalah banyaknya pegawai yang tidak masuk kerjaa akibat sakit pada bulan Maret hanya ada $0.98 \%$,bulan April, Mei, Juni jumlah pegawainya bertambah sama banyak dan pegawai yang sakitpun hanya $2.08 \%, 2.24 \%, 1.39 \%$ artinya tidak mempunyai selisih yang begitu jauh. Juli dan Agustus jumlah pegawainya kembali bertambah, persentase yang sakit $1.14 \%, 2.40 \%$. Maka dilihat dari pesentase pegawai setiap bulan selama 6 (enam) bulan terakhir tidak begitu berpengaruh terhadap kinerja pegawai karena hanya sedikit pegawai yang tidak masuk bekerja akibat sakit.

Menurut Simamora (2016:514) Kompensasi adalah bayaran yang diberikan perusahaan untuk dapat meningkatkan produktivitas para pegawai guna mencapai keunggulan yang kompetitif. Rivai (2014:607) berpendapat bahwa motivasi adalah serangkaian sikap dan nilai-nilai yang mempengaruhi individu untuk mencapai hal yang spesifik sesuai dengan tujuan individu. Sikap dan nilai-nilai tersebut merupakan suatu yang invisible yang memberikan kekuatan untuk mendorong individu bertingkah laku dalam mencapai tujuan. Tujuan dari motivasi diprediksi akan menambah enerji dalam sebuah organisasi, meningkatkan kedisiplinan pegawai Dinas Kesehatan Sumatera Barat dalam bekerja terutama untuk mempertinggi rasa tanggungjawab akan tugas yang telah diberikan sehingga pegawai dapat menyelesaikan tugasnya sebelum atau tepat pada waktu yang telah ditetapkan.

Maka dalam hal ini, para pimpinan organisasi sebaiknya mengerti tentang apa yang dibutuhkan oleh para pegawai dan mengetahui keinginan-keinginan apa saja yang bisa membuat hati para pegawai merasa puas sehingga mereka dapat meningkatkan kinerjanya, misalnya dengan memberikan bonus kepada pegawai jika target atau tujuan kerjanya telah tercapai denganbaik. Sehingga para pegawaiakan semangat melakukan hal-hal yang diminta oleh kantor dan menjalankan semua aturan kantor yang telah ditetapka seperti Apel. Dengan demikian kepuasan merupakan evaluasi yang menggambarkan seseorang atas perasaan sikapnya senang atau tidak senang maupun puas atau tidakpuas pada pekerjaannya.

\section{KAJIAN PUSTAKA \\ ProduktivitasKerja}

Produktivitas adalah kemampuan memperoleh manfaat yang sebesar-besarnya dari sarana dan prasarana yang tersedia dengan menghasilkan output yang optimal bahkan kalau mungkin yang maksimal Yani (2017:95).

\section{KepuasanKerja}

Kepuasan kerja pada dasarnya merupakan sesuatu yang bersifat individual. Setiap individu memiliki tingkat kepuasan yang berbeda-beda sesuai dengan system nilai yang berlaku pada dirinya.Makin tinggi penilaian terhadap kegiatan dirasakan sesuai dengan keinginan individu, maka makin tinggi kepuasannya terhadap kegiatan tersebut. Kepuasan kerja adalah keadaan emosional yang menyenangkan atau tidak menyenangkan dengan mana para pegawai memandang pekerjaan mereka 


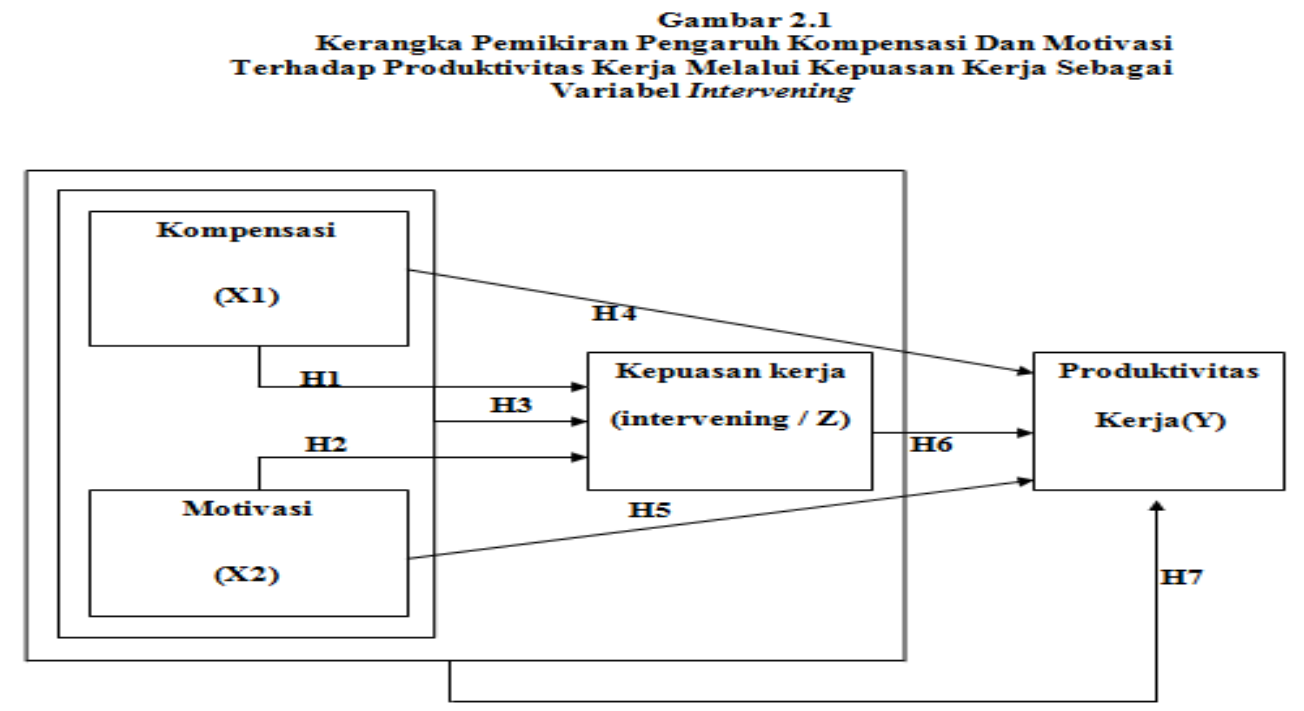

\section{Hipotesis}

H1 : Diduga Kompensasi mempunyai pengaruh terhadap produktivitas kerja pegawai.

H2 : Diduga Kompensasi mempunyai pengaruh terhadap kepuasan kerja pegawai.

H3: Diduga Kompensasi mempunyai pengaruh terhadap produktivitas kerja pegawai dengan kepuasan kerja pegawai sebagai variabel intervening.

H4 : Diduga Motivasi mempunyai pengaruh terhadap Produktivitas kerja pegawai.

H5 : Diduga Motivasi mempunyai pengaruh terhadap kepuasan kerja pegawai.

H6: Diduga Motivasi mempunyai pengaruh terhadap Produktivitas kerja pegawai dengan kepuasan kerja pegawai sebagai variabel intervening.

H7 :Diduga Kompensasi dan Motivasi mempunyai pengaruh terhadap Produktivitas kerja pegawai dengan kepuasan kerja sebagai variabel intervening.

\section{METODE PENELITIAN}

\section{Analisis Korelasi}

Analisis korelasi untuk mengetahui ada atau tidak adanya hubungan variable baik variable independen maupun variable dependen. Kolerasi dapat menghasilkan angka positif atau negatif. Jika kolerasi menghasilkan angka positif maka kolerasi bersifat searah, dan jika kolerasi menghasilkan angka negatif maka kolerasi tidaks earah. Angka kolerasi berkisar antara 0 sampai 1.Besar kecil nya angka kolerasi ditentukan kuat hubungan kedua variabel. Tabel Interprestasi nilai korelasi dalam penelitian ini terdiri atas lima interval, dimana masing-masing penilaiannya dapat dilihat pada tabel dibawah ini.

\begin{tabular}{|c|l|l|}
\hline No & Interval Koefisien & Tingkat Hubungan \\
\hline 1 & $0,00-0,199$ & Sangat Rendah \\
\hline 2 & $0,20-0,399$ & Rendah \\
\hline 3 & $0,40-0,599$ & Sedang \\
\hline 4 & $0,60-0,799$ & Kuat \\
\hline 5 & $0,80-1,000$ & Sangat Kuat \\
\hline
\end{tabular}

Sumber :Sugiyono, 2014 
Kolerasi searah mempunyai makna bahwa jika variabel bebas besar maka variabel terikatnya juga besar. Sedangkan kolerasi tidak searah bermakna bahwa jika variabel bebas besar maka variabel terikat menjadi kecil.

\section{Analisis Regresi Linier Berganda}

Penelitian ini menggunakan model analisis regresi linear untuk pembuktian hipotesis penelitian. Analisis ini akan menggunakan input berdasarkan data yang diperoleh dari kuesioner. Perhitungan statistik dalam analisis regresi linear berganda yang digunakan dalam penelitian ini adalah dengan menggunakan bantuan program SPSS (Statistical Package for Social Science). Menurut Sugiyono (2014:267) secara umum regresi berganda dapat dirumuskan sebagaiberikut :

$$
Y=a+b_{1} X_{1}+b_{2} X_{2}+b_{3} X_{3}+e
$$

Dimana :

$$
\begin{aligned}
& Y=\text { Loyalitas } \\
& Z=\text { Kepuasan pengunjung } \\
& a=\text { Standarkoefisien (konstanta) } \\
& X_{1}=\text { Citra destinasi } \\
& X_{2}=\text { Fasilitas Wisata } \\
& X_{3}=\text { Experialting Marketing } \\
& b_{1}, b_{2}, b_{3}=\text { KoefisienRegresi } \\
& e=\text { KesalahanPengganggu (standar error) }
\end{aligned}
$$

\section{PengujianSecaraParsial (Uji-t)}

Pengujian hipotesis dari data yang dapat didapat yaitu dengan menggunakan SPSS for windows version 21.0 dengan analisis uji t atau T-test. Dan dari uji $\mathrm{T}$ akan di ketahui pengaruh signifikan faktor eksternal dan faktor internal terhadap volume penjualan. Untuk mengujinya menurut (Sugiyono, 2014: 250) yaitu dengan rumus sebagai berikut :

$$
t_{\text {hitung }}=\frac{r \sqrt{n-k-1}}{\sqrt{1-r^{2}}}
$$

Keterangan: $\mathrm{r} \quad=$ KoefisienKorelasiParsial

$$
\begin{aligned}
& \mathrm{n}=\text { JumlahSampel } \\
& \mathrm{k}=\text { Jumlahvariabelindependent }
\end{aligned}
$$

\section{PengujianSecaraSimultan (Uji-F)}

Uji-F dilakukan untuk mengetahui pengaruh variabel bebas, yaitu Kualitas Pelayanan $\left(\mathrm{X}_{1}\right)$, Kualitas Produk $\left(\mathrm{X}_{2}\right)$, dan Budaya Organisasi $\left(\mathrm{X}_{3}\right)$ secara simultan berpengaruh 
terhadap variabel terikat yaitu Kinerja (Y).Untuk mengetahui apakah variabel bebas secara bersama-sama berpengaruh signifikan terhadap variabel terikat.

MenurutSugiyono (2014:266) Nilai f-hitung dapat dicari dengan rumus:

$$
\mathbf{F}_{\text {hitung }}=\frac{\mathbf{R}^{2} / \mathbf{k}}{\left(\mathbf{1}-\mathbf{R}^{2}\right) /(\mathbf{N}-\mathbf{k}-\mathbf{I}}
$$

Dimana :

$$
\begin{aligned}
& \mathrm{R}=\text { koefisienkorelasiganda } \\
& \mathrm{k}=\text { jumlahvariabel independent } \\
& \mathrm{n}=\text { jumlahsampelkonsumen }
\end{aligned}
$$

Uji t dimaksud untuk menguji signifikan pengaruh variabel bebas dan terikat secara parsial. Dimana pengujian ini membandingkan antara probabilitas signifikan dengan alpha 0,05. Dari hasil pengujian ini bila probabilitas signifikan lebih kecil dari pada alpha 0,05 maka diperoleh Ho ditolak dan Ha diterima, berarti ada hubungan dan bila probabilitas signifikan lebih besar dari pada alpha 0,05 maka Ho diterima dan Ha ditolak, berarti tidak ada hubungan.

\section{HASIL DAN PEMBAHASAN}

Analisis Regresi berganda

Analisis regresi digunakan untuk melihat pengaruh variabel independen :Kompensasi (X1) dan Motivasi (X2) secara simultan terhadap variable dependen Produktivitas Kerja (Y) dan Kepuasan Kerja (Z) sebagai variabel Intervening dengan asumsi variable independen lain dianggap konstan.

Tabel 4.17

\begin{tabular}{|c|c|c|c|c|c|c|}
\hline & \multirow[b]{2}{*}{ Model } & \multicolumn{2}{|c|}{ Unstandardized Coefficients } & \multirow{2}{*}{$\begin{array}{c}\begin{array}{c}\text { Standardized } \\
\text { Coefficients }\end{array} \\
\text { Beta }\end{array}$} & \multirow[b]{2}{*}{$\mathrm{t}$} & \multirow[b]{2}{*}{ Sig. } \\
\hline & & B & Std. Error & & & \\
\hline \multirow[t]{3}{*}{1} & (Constant) & 13,030 & 7,289 & & 1,788 & 0,079 \\
\hline & Kompensasi & 0,536 & 0,136 & 0,436 & 3,936 & 0,000 \\
\hline & Motivasi & 0,216 & 0,115 & 0,208 & 1,876 & 0,065 \\
\hline
\end{tabular}

\section{Hasil Regresi Berganda Variabel Kompensasi (X1) Dan Motivasi(X2) terhadap Kepuasan Kerja (Z) Persamaan 1 Coefficients $^{\mathrm{a}}$}

Sumber :SPSS 21.0 dan data primer yang diolah

Berdasarkan table 4.17 diatas maka dapat dilihat persamaan regresinya yaitu :

$$
\mathrm{Z}=13,030+0,436 \times 1+0,208 \times 2
$$

Dari persamaan regresi berganda di atas dapat disimpulkan bahwa :

a) Nilai konstantase besar positif sebesar 13,030; artinya jika Kompensasi dan Motivasi diabaikan (0), maka Kepuasan Kerja nilainya adalah sebesar 13,030 satuan bobot. 
b) Koefisien regresi variabel Kompensasi positif sebesar 0,436; jika Kompensasi ditingkatkan satu (1) satuan dengan asumsi Motivasi bernilai tetap (0) maka Kepuasan Kerjaakan mengalami peningkatan sebesar 0,436 satuan.

c) Koefisien regresi variabel Motivasi positif sebesar 0,208; jika Motivasi ditingkatkan satu (1) satuan dengan asumsi Kompensasi bernilai tetap (0) maka Kepuasan Kerja akan mengalami peningkatan sebesar 0,208

Tabel 4.18

\section{Hasil Regresi Berganda Variabel KompensasiDan Motivasiterhadap Produktivitas Kerja dengan Kepuasan Kerja sebagai Variabel Intervening (Persamaan 2)}

Coefficients $^{\mathrm{a}}$

\begin{tabular}{|c|c|c|c|c|c|}
\hline \multirow[b]{2}{*}{ Model } & \multicolumn{2}{|c|}{ Unstandardized Coefficients } & \multirow{2}{*}{$\begin{array}{c}\text { Standardized } \\
\text { Coefficients }\end{array}$} & \multirow[b]{2}{*}{$\mathrm{t}$} & \multirow[b]{2}{*}{ Sig. } \\
\hline & B & Std. Error & & & \\
\hline 1 (Constant) & 7,510 & 2,684 & & 2,798 & ,007 \\
\hline Kompensasi & ,409 & 055 & ,563 & 7,491 & 000 \\
\hline Motivasi & , 106 & 043 & , 172 & 2,490 & 015 \\
\hline Kepuasan & ,20,37 & ,045 & ,400 & 5,227 & ,000 \\
\hline
\end{tabular}

Sumber :SPSS 21.0 dan data primer yang diolah

Berdasarkan table 4.18 diatas maka dapat dilihat persamaan regresinya yaitu :

$$
\mathrm{Y}=7,510+0,563 \mathrm{X} 1+0,172 \times 2+0,400 Z
$$

Dari persamaan regresi berganda di atas dapat disimpulkan bahwa :

a) Nilai konstantase besar positif sebesar 7,510; artinya jika Kompensasi, Motivasi dan Kepuasan Kerja diabaikan (0), maka Produktivitas Kerja nilainya adalah sebesar 7,510 satuan bobot.

b) Koefisien regresi variabel Kompensasi positif sebesar 0,563; jika Kompensasi ditingkatkan satu (1) satuan dengan asumsi Motivasi dan Kepuasan Kerja bernilai tetap (0) maka Produktivitas Kerja akan mengalami peningkatan sebesar 0,563 satuan.

c) Koefisien regresi variabel Motivasi positif sebesar 0,172; jika Motivasi ditingkatkan satu (1) satuan dengan asumsi Kompensasi dan Kepuasan Kerja bernilai tetap (0) maka Produktivitas Kerja akan mengalami peningkatan sebesar 0,172 satuan.

d) Koefisien regresi variabel Kepuasan Kerja positif sebesar 0,400; jika Kepuasan Kerja ditingkatkan satu (1) satuan dengan asumsi Kompensasi dan Motivasi bernilai tetap (0) maka Produktivitas Kerja akan mengalami peningkatan sebesar0 ,400.

\section{Uji Analisis Jalur (Path Analysis)}

\section{Koefisien Jalur Model I}

Berdasarkan ersamaan yang di dapat dari analisis regresi berganda pada model 1 maka dapat dirumuskan diagram jalur model 1 sebagai berikut :

$$
Z=0,436 X_{1}+0,208 X_{2}+e
$$




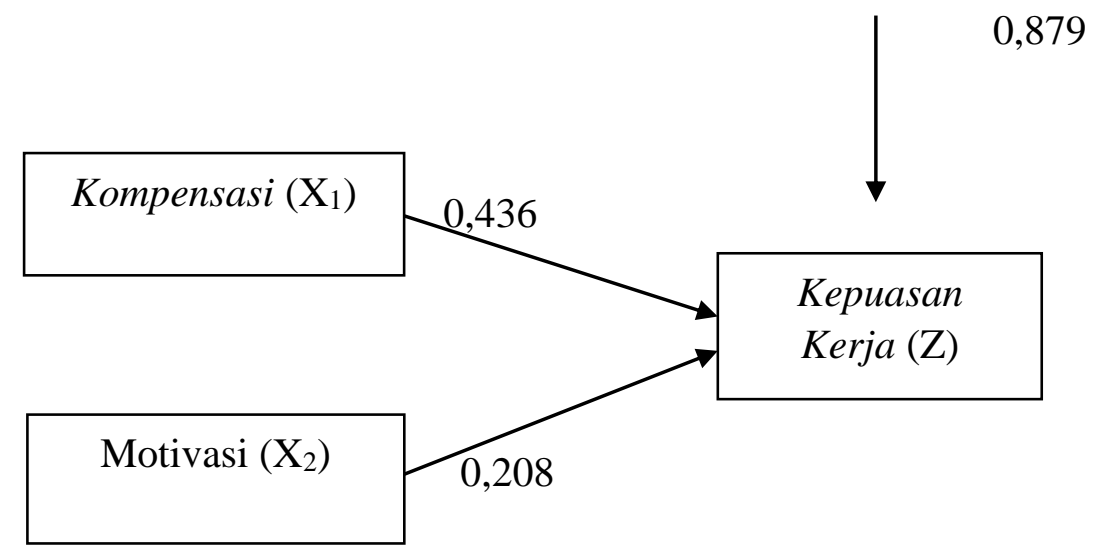

Gambar 4.5

Diagram Jalur 1

$* e=\mathrm{V} 1-\mathrm{R}^{2}$

$=\mathrm{V} 1-0,227$

$=0,879$

\section{Koefisien Jalur Model II}

Berdasarkan persamaan yang di dapat dari analisis regresi berganda pada model 2 maka dapat dirumuskan diagram jalur model 2 sebagai berikut :

$$
\mathrm{Y}=0,563 \mathrm{X}_{1}+0,172 \mathrm{X}_{2}+0,400 \mathrm{Z}+\mathrm{e}
$$

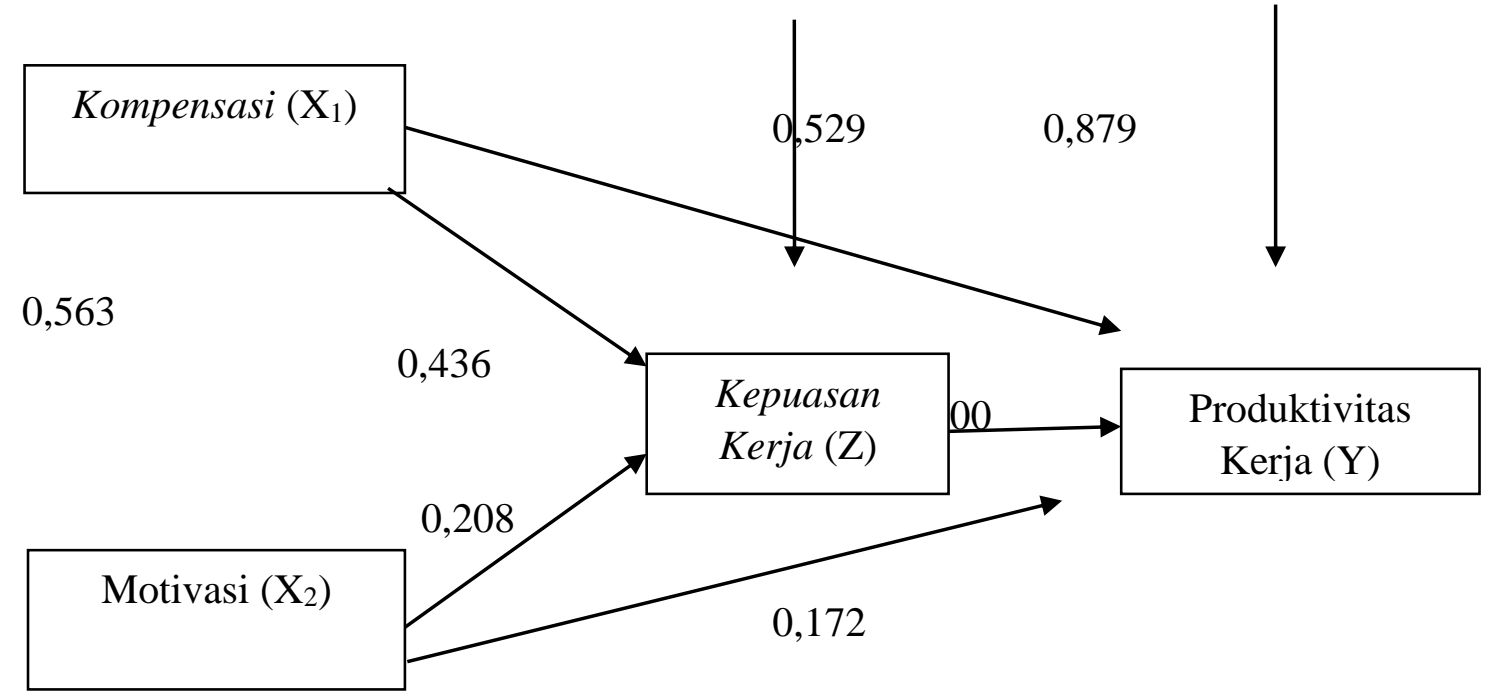

Diagram Jalur II

$* e=\mathrm{V} 1-\mathrm{R}^{2}$ 
$=\mathrm{V} 1-0,720$

$=0,529$

\section{InterprestasiUji Analisis Jalur (Path Analysis)}

Berdasarkan diagram jalur yang telah dirumuskan maka dapat disumpulkan pengaruh lansung dan tidak lansung sebagai berikut :

1. Pengaruh dari Kompetensi $\left(\mathrm{X}_{1}\right)$ ke Produktivitas Kerja (Y)

a. Pengaruh Lansung $=0,563$

b. Pengaruh tidak lansung melalui Kepuasan Kerja $(\mathrm{Z})=0,436$ x 0,400

$=0,174$

c. Total pengaruh $=0,563>0,174$

Maka dapat disimpulkan bahwa pengaruh tidak lansung Kompetensi $\left(\mathrm{X}_{1}\right)$ lebih kecil dibandingkan pengaruh langsung terhadap Produktivitas Kerja (Y).

2. Pengaruh dari Motivasi $\left(\mathrm{X}_{2}\right)$ ke Produktivitas Kerja (Y)

a. Pengaruh Lansung $=0,173$

b. Pengaruh tidak lansung melalui Kepuasan Kerja $(Z)=0,208 \times 0,400$

c. Total pengaruh $=0,173>0,083$

$$
=0,083
$$

Maka dapat disimpulkan bahwa pengaruh lansung Motivasi $\left(\mathrm{X}_{2}\right)$ lebih besar dibandingkan pengaruh tidak lansunng terhadap Produktivitas Kerja (Y).

3. Pengaruh dari Kepuasan Kerja (Z) ke Produktivitas Kerja (Y)

a. Pengaruh Lansung $=0,400$

\section{Koefisien Determinasi $\left(\mathbf{R}^{\mathbf{2}}\right)$}

Koefisien determinasi $\left(\mathrm{R}^{2}\right)$ digunakan untuk mengetahui kontribusi variabel bebas dalam menjelaskan variabel terikat. Semakin besar nilai koefisien determinasi akan meenunjukkan semain besar pula pengaruh variabel bebas terhadap variabel terikat (Imam Ghozali, 2012: 79). Analisa koefisien determinasi dalam regresi linear berganda digunakan untuk mengetahui persentase sumbangan pengaruh variabel independen yang terdiri dari Kompensasi $\left(\mathrm{X}_{1}\right)$, Motivasi $\left(\mathrm{X}_{2}\right)$ secara simultan terhadap Produktivitas Kerja (Y) dengan dan Kepuasan Kerja $(Z)$ sebagai variabel intervening

Tabel 4.1

Hasil Koefisien Determinasi Variabel Kompensasi (X1) Dan Motivasi(X2) terhadap Kepuasan Kerja (Z) Persamaan 1

\begin{tabular}{|c|l|c|l|l|}
\hline Model & $\mathbf{R}$ & R Square & $\begin{array}{l}\text { Adjusted } \\
\text { Square }\end{array}$ & $\begin{array}{l}\text { Std. Error of } \\
\text { the Estimate }\end{array}$ \\
\hline 1 & $0,477^{\mathrm{a}}$ & 0,227 & 0,203 & 8,407 \\
\hline
\end{tabular}

Sumber :SPSS 21.0 dan data primer yang diolah

Berdasarkan tabe 14.19di atas diperoleh angka Adjusted R Square sebesar 0,203 atau 20,3\%, hal ini menunjukkan bahwa persentase sumbangan variabel independen Kompensasi dan Motivasi terhadap variabe ldependen Kepuasan Kerja sebesar 0,203 atau 20,3\%.Sedangkan sisanya sebesar dipengaruhi oleh variabel lain di luar penelitian ini seperti harapan pegawai, Produktivitas Kerja dan lain- lain. 
Tabel 4.21

Hasil Koefisien Determinasi Variabel Kompensasi (X1) dan Motivasi(X2) terhadap Produktivitas Kerja (Y) dengan Kepuasan Kerja (Z) sebagai variabel InterveningPersamaan 2

\begin{tabular}{|c|l|c|l|l|}
\hline Model & $\mathbf{R}$ & R Square & $\begin{array}{l}\text { Adjusted } \\
\text { Square }\end{array}$ & $\begin{array}{l}\text { Std. Error of the } \\
\text { Estimate }\end{array}$ \\
\hline 2 & $0,848^{\mathrm{a}}$ & 0,720 & 0,706 & 3,020 \\
\hline
\end{tabular}

Sumber :SPSS 21.0 dan data primer yang diolah

Berdasarkan tabe $14.21 \mathrm{di}$ atas diperoleh angka Adjusted R Square sebesar0,706 atau $70,6 \%$, hal ini menunjukkan bahwa persentase sumbangan variabel independen Kompensasi, Motivasi dan Kepuasan Kerja terhadap variabel dependen Produktivitas Kerja sebesar 0,706 atau 70,6\%.Sedangkan sisanya sebesar dipengaruhi oleh variabel lain di luar penelitian ini seperti harapan pegawai, Produktivitas Kerja dan lain- lain.

\section{Uji HipotesisSecaraSimultan (F)}

Uji F dimaksud untuk menguji hipotesis pertama dari penelitian yang menyatakan bahwa variabel kompensasi, motivasi dan kepuasan kerja sebagai variabel intervening mempunyai pengaruh yang signifikan terhadap produktivitas kerja. Hasil Uji F menggunakan taraf signifikan 0,05 (uji 2sisi). Hasilnya dapat dilihat pada tabel 4.22 di bawah ini:

Tabel 4.12

\section{PengujianHipotesisVariabelSecaraSimultanPersamaan I}

ANOVA $^{\mathrm{a}}$

\begin{tabular}{|c|c|c|c|c|c|}
\hline Model & $\begin{array}{l}\text { Sum of } \\
\text { Squares }\end{array}$ & df & Mean Square & $\mathrm{F}$ & Sig. \\
\hline 1 Regression & 1310,946 & 2 & 655,473 & 9,274 &, $000^{\mathrm{b}}$ \\
\hline Residual & 4452,584 & 63 & 70,676 & & \\
\hline Total & 5763,530 & 65 & & & \\
\hline
\end{tabular}

Sumber :SPSS 21.0 dan data primer yang diolah

Dari tabel annova didapatkan sig yaitu $0,000<0,05 \mathrm{~F}_{\text {hitung }}$ dari angka ini penulis berkesimpulan Kompensasi dan Motivasi mempunyai pengaruh yang berarti atau signifikan dengan Kepuasan Kerja, berarti dapat disimpulkan bahwa Ho ditolak dan $\mathrm{H}_{3}$ diterima, sehingga dapat disimpulkan bahwa jika dilakukan pengujian secara bersama-sama antara Kompensasi dan Motivasi maka mempunyai pengaruh yang signifikan terhadap Kepuasan Kerja.

$\mathrm{H}_{\mathrm{O}}=$ Tidak ada pengaruh yang signifikan antara Kompensasi, Motivasi terhadap Kepuasan Kerja.

$\mathrm{H}_{3}=$ Ada pengaruh yang signifikan antara Kompensasi dan Motivasi terhadap Kepuasan Kerja. 
Tabel 4.20

\section{Pengujian Hipotesis Variabel Secara Simultan Persamaan II}

Coefficients $^{\mathrm{a}}$

\begin{tabular}{|c|c|c|c|c|c|}
\hline \multirow[b]{2}{*}{ Model } & \multicolumn{2}{|c|}{$\begin{array}{c}\text { Unstandardized } \\
\text { Coefficients }\end{array}$} & \multirow{2}{*}{$\begin{array}{c}\begin{array}{c}\text { Standardized } \\
\text { Coefficients }\end{array} \\
\text { Beta }\end{array}$} & \multirow[b]{2}{*}{$\mathrm{t}$} & \multirow[b]{2}{*}{ Sig. } \\
\hline & B & Std. Error & & & \\
\hline 1 (Constant) & 7,510 & 2,684 & & 2,798 &, 007 \\
\hline Kompensasi & ,409 & 055 &, 563 & 7,491 &, 000 \\
\hline Motivasi & , 106 & ,043 &, 172 & 2,490 &, 015 \\
\hline Kepuasan & ,237 &, 045 & ,400 & 5,227 &, 000 \\
\hline
\end{tabular}

Sumber :SPSS 21.0 dan data primer yang diolah

Dari tabel annova didapatkan sig yaitu $0,000<0,05 \mathrm{~F}_{\text {hitung }}$ dari angka ini penulis berkesimpulan Kompensasi, Motivasi dan Kepuasan Kerja sebagai variabel intervening mempunyai pengaruh yang berarti atau signifikan dengan Produktivitas Kerja pegawai, berarti dapat disimpulkan bahwa Ho ditolak dan $\mathrm{H}_{7}$ diterima, sehingga dapat disimpulkan bahwa jika dilakukan pengujian secara bersama-sama antara Kompensasi, Motivasi dan Kepuasan Kerja sebagai variabel intervening maka mempunyai pengaruh yang signifikan terhadap Produktivitas Kerja.

$\mathrm{H}_{\mathrm{O}}=$ Tidak ada pengaruh yang signifikan antara Kompensasi, Motivasi dan Kepuasan Kerja sebagai variabel intervening terhadap Produktivitas Kerja.

$\mathrm{H}_{7}=$ Ada pengaruh yang signifikan antara Kompensasi, Motivasi dan Kepuasan Kerja sebagai variabel intervening terhadap Produktivitas Kerja.

\section{Uji HipotesisSecaraParsial(Uji t)}

Uji t dimaksud untuk menguji signifikan pengaruh variabel bebas dan terikat secara parsial. Dimana pengujian ini membandingkan antara probabilitas signifikan dengan alpha 0,05. Dari pengujian pada variable Kompensasi, Motivasi dan KepuasanKerjater sebagai variabel intervening terhadap produktivitas kerja maka dapat disajikan pada table berikut ini

\section{Tabel 4.21}

\section{Pengujian Secara Parsial Atas Kompensasi dan Motivasi Terhadap Kepuasan Kerja (Persamaan I) \\ Coefficients $^{\mathrm{a}}$}

\begin{tabular}{|l|c|c|c|c|c|}
\hline \multirow{2}{*}{ Model } & \multicolumn{2}{|c|}{$\begin{array}{c}\text { Unstandardized } \\
\text { Coefficients }\end{array}$} & $\begin{array}{c}\text { Standardized } \\
\text { Coefficients }\end{array}$ & & \\
\cline { 2 - 4 } & $\mathrm{B}$ & Std. Error & Beta & $\mathrm{t}$ & Sig. \\
\hline
\end{tabular}




\begin{tabular}{|c|c|c|c|c|c|}
\hline (Constant) & 13,030 & 7,289 & & 1,788 & 079 \\
\hline Kompensasi &, 536 & , 136 & ,436 & 3,936 &, 000 \\
\hline Motivasi & ,216 &, 115 & ,208 & 1,876 &, 065 \\
\hline
\end{tabular}

Sumber :SPSS 21.0 dan data primer yang diolah

Berdasarkan table 4.21 di atas maka dapat disimpulkan sebagai berikut :

1. Kompensasi mempunyai pengaruh yang sigifikan terhadap Kepuasan Kerja.

Dari tabel diatas di ketahui tingkat siginifikan $(0,000<0,05)$, artinya secara parsial ada pengaruh yang signifikan antara Kompensasi dengan Kepuasan Kerja. Dengan demikian Ho Tolak dan $\mathrm{H}_{1}$ diterima.

$$
\begin{aligned}
\mathrm{H}_{\mathrm{O}}= & \text { Tidak ada pengaruh yang signifikan antara Kompensasi terhadap } \\
& \text { Kepuasan Kerja } \\
\mathrm{H}_{1}= & \text { Ada pengaruh yang signifikan antara Kompensasi terhadap Kepuasan } \\
& \text { Kerja. }
\end{aligned}
$$

2. Motivasi mempunyai pengaruh yang signifikan terhadap Kepuasan Kerja.

Dari tabel diatas diketahui tingkat siginifikan $(0,065>0,05)$, artinya secara parsial tidak ada pengaruh yang signifikan antara Motivasi dengan Kepuasan Kerja. Dengan demikian Ho diterima dan $\mathrm{H}_{2}$ ditolak.

$\mathrm{Ho}_{\mathrm{O}}=$ Tidak ada pengaruh yang signifikan antara Motivasi terhadap Kepuasan Kerja.

$\mathrm{H}_{2}=$ Ada pengaruh yang signifikan antara Motivasi terhadap Kepuasan Kerja .

Tabel 4.2

\begin{tabular}{|c|c|c|c|c|c|}
\hline \multirow[b]{2}{*}{ Model } & \multicolumn{2}{|c|}{$\begin{array}{c}\text { Unstandardized } \\
\text { Coefficients }\end{array}$} & \multirow{2}{*}{$\begin{array}{c}\begin{array}{c}\text { Standardized } \\
\text { Coefficients }\end{array} \\
\text { Beta }\end{array}$} & \multirow[b]{2}{*}{$\mathrm{t}$} & \multirow[b]{2}{*}{ Sig. } \\
\hline & B & Std. Error & & & \\
\hline 1 (Constant) & 7,510 & 2,684 & & 2,798 & ,007 \\
\hline Kompensasi & ,409 &, 055 &, 563 & 7,491 &, 000 \\
\hline Motivasi & , 106 & ,043 & , 172 & 2,490 &, 015 \\
\hline Kepuasan & ,237 & 045 & ,400 & 5,227 & ,000 \\
\hline
\end{tabular}

Pengujian Secara Parsial Atas Kompensasi dan Motivasi Terhadap Produktivitas Kerja dengan Kepuasan Kerja Sebagai Variabel Intervening (Persamaan II)

Coefficients $^{\mathrm{a}}$

Sumber :SPSS 21.0 dan data primer yang diolah

Berdasarkan tabel 4.25 di atas maka dapat disimpulkan sebagai berikut :

1. Kompensasi mempunyai pengaruh yang sigifikan terhadap Produktivitas Kerja.

Dari tabel diatas di ketahui tingkat siginifikan $(0,000<0,05)$, artinya secara parsial ada pengaruh yang signifikan antara Kompensasi dengan Produktivitas Kerja. Dengan demikian Ho Tolak dan $\mathrm{H}_{4}$ diterima. 
$\mathrm{H}_{\mathrm{O}}=$ Tidak ada pengaruh yang signifikan antara Kompensasi terhadap Produktivitas Kerja.

$\mathrm{H}_{4}=$ Ada pengaruh yang signifikan antara Kompensasi terhadap Produktivitas Kerja.

2. Motivasi mempunyai pengaruh yang signifikan terhadap Produktivitas Kerja

Dari tabel diatas diketahui tingkat siginifikan $(0,015<0,05)$, artinya secara parsial ada pengaruh yang signifikan antara Motivasi dengan Produktivitas Kerja. Dengan demikian Ho ditolak dan $\mathrm{H}_{5}$ diterima.

\section{$\mathrm{H}_{\mathrm{O}}=$ Tidak ada pengaruh yang signifikan antara Motivasi terhadap Produktivitas Kerja. \\ $\mathrm{H}_{5}=$ Ada pengaruh yang signifikan antara Motivasi terhadap Produktivitas Kerja.}

3. Kepuasan Kerja mempunyai pengaruh yang signifikan terhadap Produktivitas Kerja

Dari tabel diatas diketahui tingkat siginifikan $(0,000<0,05)$, artinya secara parsial ada pengaruh yang signifikan antara Kepuasan Kerja dengan Produktivitas Kerja. Dengan demikian Ho ditolak dan $\mathrm{H}_{6}$ diterima.

$\mathrm{Ho}_{\mathrm{O}}=$ Tidak ada pengaruh yang signifikan antara Kepuasan Kerja terhadap Produktivitas Kerja.

$\mathrm{H}_{6}=$ Ada pengaruh yang signifikan antara Kepuasan Kerja terhadap Produktivitas Kerja.

Maka dapat disimpulkan bahwa Ho ditolak dan Ha diterima. Selanjut nya ketujuh hipotesi spenelitian yang dikemukakan sebelumnya dapat disimpulkan pada tabel 4.26sebagaiberikut :

Tabel 4.26

Hasil Pengujian Hipotesis Penelitian

\begin{tabular}{|c|c|c|c|c|}
\hline $\begin{array}{l}\text { Hipotesi } \\
\text { s }\end{array}$ & Pernyataan & Sig. & $\begin{array}{l}\text { Pembandin } \\
\text { g }\end{array}$ & Keputusan \\
\hline H1 & $\begin{array}{l}\text { DidugaKompensasimempunyaipen } \\
\text { garuhterhadapproduktivitas } \\
\text { kerjapegawai. }\end{array}$ & 0,000 & 0,05 & Diterima \\
\hline $\mathrm{H} 2$ & $\begin{array}{l}\text { Diduga } \\
\text { Motivasimempunyaipengaruhterha } \\
\text { dapkepuasankerjapegawai. }\end{array}$ & 0,060 & 0,05 & Ditolak \\
\hline $\mathrm{H} 3$ & $\begin{array}{l}\text { Diduga Kompensasi dan Motivasi } \\
\text { berpengaruh secara bersama -sama } \\
\text { terhadap kepuasan kerja pegawai }\end{array}$ & 0,000 & 0,05 & Diterima \\
\hline $\mathrm{H} 4$ & $\begin{array}{l}\text { Diduga kompensasi berpengaruh } \\
\text { terhadap produktivitas kerja }\end{array}$ & 0,000 & 0,05 & Diterima \\
\hline H5 & $\begin{array}{l}\text { Diduga motivasi berpengaruh } \\
\text { terhadap produktivitas kerja }\end{array}$ & 0,015 & 0,05 & Diterima \\
\hline H6 & $\begin{array}{l}\text { Diduga kepuasan kerja berpengaruh } \\
\text { terhadap produktivitas kerja }\end{array}$ & 0,000 & 0,05 & Diterima \\
\hline
\end{tabular}




\begin{tabular}{|l|lr|r|r|r|} 
H7 & \multicolumn{2}{|l|}{$\begin{array}{l}\text { Diduga kompensasi, motivasi dan } \\
\text { kepuasan sebagai variabel } \\
\text { intervening berpengaruh terhadap }\end{array}$} & 0,000 & $\mathbf{0 , 0 5}$ & Diterima \\
produktivitas kerja. & &
\end{tabular}

Sumber :SPSS 21.0 dan data primer yang diolah

Tabel 4.26

Hasil Pengujian Part Analysis

\begin{tabular}{|l|c|c|c|}
\hline \multicolumn{1}{|c|}{ Pengaruh Variabel } & $\begin{array}{c}\text { Pengaruh } \\
\text { Langsung }\end{array}$ & $\begin{array}{c}\text { Pengaruh Tidak } \\
\text { Langsung }\end{array}$ & Pengaruh Total \\
\hline $\begin{array}{l}\text { Kompensasi (X1) } \rightarrow \text { Kepuasan } \\
\text { Kerja (Z) }\end{array}$ & 0,436 & - & 0,436 \\
\hline $\begin{array}{l}\text { Motivasi (X2) } \rightarrow \text { Kepuasan } \\
\text { Kerja (Z) }\end{array}$ & 0,208 & - & 0,208 \\
\hline $\begin{array}{l}\text { Kompensasi (X1) } \\
\rightarrow \text { Produktivitas Kerja (Y) }\end{array}$ & 0,563 & - & 0,563 \\
\hline $\begin{array}{l}\text { Motivasi (X2) } \rightarrow \text { Produktivitas } \\
\text { Kerja (Y) }\end{array}$ & 0,172 & 0,174 & 0,400 \\
\hline $\begin{array}{l}\text { Kepuasan Kerja(Z) } \\
\rightarrow \text { Produktivitas Kerja (Y) }\end{array}$ & 0,400 & 0,083 & 0,255 \\
\hline $\begin{array}{l}\text { Kompensasi (X1) } \rightarrow \text { Kepuasan } \\
\text { Kerja(Z) } \rightarrow \text { Produktivitas Kerja } \\
(Y)\end{array}$ & 0,172 & & \\
\hline $\begin{array}{l}\text { Motivasi (X1) } \rightarrow \text { Kepuasan } \\
\text { Kerja(Z) } \rightarrow \text { Produktivitas Kerja } \\
(Y)\end{array}$ & & & \\
\hline
\end{tabular}

Sumber : SPSS 21.0 dan data primer yang diolah

Kesimpulan:

Pengaruh langsung Kompensasi terhadap Produktivitas Kerja sebesar 0.563 sedangkan pengaruh tidak langsung Kompensasi terhadap Produktivitas Kerja melalui Kepuasan Kerja sebesar 0.737. Sehingga dapat disimpulkan bahwa pengaruh langsung Kompensasi terhadap Produktivitas Kerja lebih besar dibandingkan pengaruh tidak langsung Kompensasi terhadap Produktivitas Kerja melalui Kepuasan Kerja.

Pengaruh langsung Motivasi terhadap Produktivitas Kerja sebesar 0.172 sedangkan pengaruh tidak langsung Motivasi terhadap Produktivitas Kerja melalui Kepuasan Kerja sebesar 0.255. Sehingga dapat disimpulkan bahwa pengaruh langsung motivasi terhadap Produktivitas Kerja lebih kecil dibandingkan pengaruh tidak langsung motivasi terhadap Produktivitas Kerja melalui Kepuasan Kerja.

Dari Berdasarkan hasil penelitian yang telah dilakukan, maka penulis dapat mengimplikasikan hal-ha lsebagai berikut:

1. Terdapat pengaruh Positif dan signifikan Kompensasi terhadap Kepuasan Kerja Dinas Kesehatan Sumatera Barat. Dimana tingkat signifikan lebih kecil dari dari alpha $(0,00<0,05)$. Dengan demikian Ho Tolak dan H1 diterima yang berarti dapat disimpulkan Kompensasi berpengaruh positif signifikan terhadap Kepuasan Kerja Dinas Kesehatan Sumatera Barat. Semakin baik Kompensasi yang diberikan maka 
semakin tinggi tingkat Kepuasan Kerja. Hasil penelitian ini sejalan dengan penelitian yang dilakukan oleh

2. Terdapat pengaruh positif dan signifikan Motivasi terhadap Kepuasan Kerja Dinas Kesehatan Sumatera Barat. Dimana tingkat signifikan lebih kecil dari alpha $(0,060>$ 0,05). Dengan demikian Ho Terimadan Hzditolak yang berarti dapat disimpulkan Motivasi berpengaruh positif signifikan terhadap Kepuasan Kerja Dinas Kesehatan Sumatera Barat, semakin terjangkaunya Motivasi yang diberikan maka semakin tinggi pula Kepuasan Kerja. Hasil penelitian ini sejalan dengan penelitian yang dilakukan oleh

3. Terdapat pengaruh positif dan signifikan Kompensasi dan Motivasisecara bersamasama terhadap Kepuasan Kerja Dinas Kesehatan Sumatera Barat. Dimana tingkat signifikan lebih kecil dari alpha $(0,000<0,05)$. Dengan demikian Ho Tolak dan H3diterima yang berarti dapat disimpulkan Kompensasi Motivasi berpengaruh positif signifikan secara bersama-sama terhadap Kepuasan Kerja Dinas Kesehatan Sumatera Barat, apabila Kompensasi dan Motivasi diperhatikan secara bersamaan maka akan meningkatkan Kepuasan Kerja.

4. Terdapat pengaruh positif dan signifikan Kompensasi terhadap Produktivitas Kerja Dinas Kesehatan Sumatera Barat. Dimana tingkat signifikan lebih kecil dari dari alpha $(0,00<0,05)$. Dengan demikian Ho Tolak dan H4diterima yang berarti dapat disimpulkan Kompensasi berpengaruh positif signifikan terhadap Produktivitas Kerja Dinas Kesehatan Sumatera Barat. Semakin baik Kompensasi maka semakin meningkat Produktivitas Kerja. Hasil penelitian ini sejalan dengan penelitian yang dilakukan oleh

5. Terdapat pengaruh positif dan signifikan Motivasi terhadap Produktivitas Kerja Dinas Kesehatan Sumatera Barat. Dimana tingkat signifikan lebih kecil dari dari alpha $(0,015<0,05)$. Dengan demikian Ho Tolak dan Hsditerima yang berarti dapat disimpulkan Motivasi berpengaruh positif signifikan terhadap Produktivitas Kerja Dinas Kesehatan Sumatera Barat. Semakin baik Motivasi maka semakin meningkat Produktivitas Kerja. Hasil penelitian ini sejalan dengan penelitian yang dilakukan oleh

6. Terdapat pengaruh positif dan signifikan Kepuasan Kerja terhadap Produktivitas Kerja Dinas Kesehatan Sumatera Barat. Dimana tingkat signifikan lebih kecil dari dari alpha $(0,00<0,05)$. Dengan demikian Ho Tolak dan Hoditerima yang berarti dapat disimpulkan Kepuasan Kerja berpengaruh positif signifikan terhadap Produktivitas Kerja Dinas Kesehatan Sumatera Barat. Semakin tinggi loyalitas maka semakin menunjukan Produktivitas Kerja. Hasil penelitian ini sejalan dengan penelitian yang dilakukan oleh

7. Terdapat pengaruh yang signifikan secara bersama-sama antara Kompensasi, Motivasi dan Kepuasan Kerja sebagai variabel intervening terhadap Produktivitas Kerja pada Dinas Kesehatan Sumatera Barat. Dimana tingkat signifikan $(0,00>0,05)$. Dengan demikian Ho Tolak danH $\mathbf{H}_{7}$ diterima yang berarti dapat disimpulkan Kompensasi, Motivasi dan Kepuasan Kerja sebagai variabel intervening berpengaruh secara bersama-sama terhadap Produktivitas Kerja.

8. Kontribusi variabel Kompensasi dan Motivasi terhadap Kepuasan Kerja berpengaruh sebesar 20,3\% sedangkan sisanya 79,7\% dipengaruhi oleh faktor lain seperti Produktivitas Kerja, harapan pegawai, Motivasi dan media social.

9. Kontribusi variabel Kompensasi dan Motivasi terhadap Produktivitas Kerja denganKepuasan Kerja sebagai variabel intervening berpengaruh sebesar 70,6\% sedangkan sisanya 29,4\% dipengaruhi oleh faktor lain. 


\section{KESIMPULAN DAN SARAN} berikut :

Berdasarkan kesimpulan di atas, maka penulisakan memberikan saran - saran sebagai

1. Bagi Dinas Kesehatan Sumatera Barat

a.Untuk lebih memperhatikan Kompensasi baik secara online maupun offline karena terbukti dapat meningkatkan Kepuasan Kerja dan Produktivitas Kerja.

b. Lebih memperhatikan Motivasi dengan membandingkan dengan layanan, fasilitas dan mamfaat jasa yang diberikan karena terbukti dapat meningkatkan Kepuasan Kerja dan Produktivitas Kerja.

\section{Bagi Peneliti Selanjutnya}

Peneliti selanjutnya diharapkan untuk mengembangkan hasil penelitian ini dan melibatkan variabel-variabel yang relevan berkaitan dengan Produktivitas Kerja dan Kepuasan Kerja. Dengan harapan hasil penelitian lebih akurat dan memiliki manfaat yang jauh lebih besar, sehingga perusahaan dapat meningkatkan produktivitas pada tahun-tahun berikutnya.

\section{DAFTAR PUSTAKA}

Simamora, H. (2016;514). Manajemen sumber daya manusia.

Rivai, V., \& Murni, S. (2014:607). Education management: analisis teori dan praktik.

Afriansyah, A., \& NUGRAHENI, R. (2014). Pengaruh Kompensasi Dan Konflik Kerja Terhadap Kinerja Karyawan (Studi pada Kantor PT. Pos Indonesia (PERSERO) Mail Processing Center Semarang) (Doctoral dissertation, Fakultas Ekonomika dan Bisnis).

Agusta, L. (2013). Pengaruh pelatihan dan motivasi kerja terhadap kinerja karyawan CV Haragon Surabaya. Agora, 1(3), 1399-1408.

As' ad, M. (2012). Finding the best ARIMA model to forecast daily peak electricity demand.

Basuki, A. T., \& Prawoto, N. (2016). Analisis Regresi Dalam Penelitian

Ekonomi \& Bisis (Dilengkapi Aplikasi Spss \& Eviews).

Dwi, P. (2008). Mandiri Belajar SPSS. Cetakan pertama. Yogyakarta: Mediakom.

Hasibuan, M. SP, 2014. Manajemen sumber daya Manusia, Bumi Aksara, Jakarta.

Hasibuan, Malayu SP. "Organisasi dan motivasi." Jakarta: Bumi Aksara (2003).

Ibrahim, L. T., Yunus, M., \& Amri, A. (2018). Pengaruh Budaya Organisasi Kompensasi dan Motivasi Berprestasi Terhadap Kinerja Dosen Tetap Serta Dampaknya Pada Mutu Pendidikan Universitas Abulyatama Aceh. Jurnal Humaniora, 2(1), 61-73.

Iswara, I. M. W., \& Subudi, M. Peran Mediasi Motivasi Kerja Dalam Pengaruh Kompensasi Terhadap Semangat Kerja.

Kadarisman, M. (2011). Manajemen kompensasi.

Mada, I. G. N. C. W., Sintaasih, D. K., \& Subudi, M. (2017, July). Pengaruh Keadilan Organisasional Terhadap Motivasi Dan Kinerja Karyawan. In Forum Manajemen STIMI Handayani Denpasar (Vol. 15, No. 2, pp. 1-18).

Muljani, N. (2004). Kompensasi sebagai motivator untuk meningkatkan kinerja karyawan. Jurnal Manajemen dan Kewirausahaan, 4(2), 108-122.

Nurcahyani, N. M., \& Adnyani, I. D. (2016). Pengaruh kompensasi dan motivasi terhadap kinerja karyawan dengan kepuasan kerja sebagai variabel intervening. E-Jurnal Manajemen Universitas Udayana, 5(1). 
Onibala, R., Kojo, C., \& Uhing, Y. (2017). Pengaruh Tingkat Pendidikan Dan Kompensasi Terhadap Kinerja Pegawai Pada Dinas Kesehatan Provinsi Sulawesi Utara. Jurnal Riset Ekonomi, Manajemen, Bisnis dan Akuntansi, 5(2).

Onibala, R., Kojo, C., \& Uhing, Y. (2017). Pengaruh Tingkat Pendidikan Dan Kompensasi Terhadap Kinerja Pegawai Pada Dinas Kesehatan Provinsi Sulawesi Utara. Jurnal Riset Ekonomi, Manajemen, Bisnis dan Akuntansi, 5(2).

Paita, S., Tewal, B., \& Greis, M. (2015). Pengaruh Kompensasi dan Lingkungan Kerja Terhadap Kinerja Pegawai Melalui Motivasi Kerja Pada Balai Pendidikan dan Pelatihan Keagamaan Manado. Jurnal EMBA: Jurnal Riset Ekonomi, Manajemen, Bisnis dan Akuntansi, 3(3).

Pati, N., \& Lee, J. (2016). Benchmarking presidents' compensations in institutions of higher education relative to sustainability and other institutional practices. Benchmarking: An International Journal, 23(6), 1500-1521.

Potale, R., \& Uhing, Y. (2015). Pengaruh Kompensasi dan Stres Kerja Terhadap Kepuasan Kerja Karyawan Pada PT. Bank Sulut Cabang Utama Manado. Jurnal EMBA: Jurnal Riset Ekonomi, Manajemen, Bisnis dan Akuntansi, 3(1).

Prabu, A. (2005). Pengaruh motivasi terhadap kepuasan kerja pegawai badan koordinasi keluarga berencana nasional kabupaten muara enim. Jurnal Manajemen \& Bisnis Sriwijaya, 3(6), 1-25.

Putra, U. S. (2012). Metode Penelitian.

Rahmawati, F. (2016). Pengaruh motivasi dan kompensasi terhadap Kinerja karyawan dengan kepuasan kerja Sebagai variabel intervening (Studi Empiris pada Kantor DPPKAD Kabupaten Karanganyar) (Doctoral dissertation, Universitas Muhammadiyah Surakarta).

Riduwan, A. (2009). Rumus dan data dalam analisis statistika. Bandung (ID): Alfabeta.

Riduwan, M. B. A. (2007). Skala pengukuran variabel-variabel penelitian. Alfabeta. Bandung.

Rivai, V., \& Murni, S. (2016). Education management: analisis teori dan praktik.

Rumakway, M. (2013). Pengaruh Kompensasi dan karakteristik pekerjaan terhadap kepuasan kerja karyawan. Majalah Ekonomi, 17(1).

Sadili, S. (2006). Manajemen Sumber Daya Manusia. Bandung: pustaka setia.

Sahlan, N. I., Mekel, P. A., \& Trang, I. (2015). Pengaruh Lingkungan Kerja, Kepuasan Kerja dan Kompensasi terhadap Kinerja Karyawan pada PT. Bank Sulut Cabang Airmadidi. Jurnal EMBA: Jurnal Riset Ekonomi, Manajemen, Bisnis dan Akuntansi, 3(1).

Sanusi, A. (2011). Metodologi penelitian bisnis.

Sarwono, J., Arikunto, M., \& Arikunto, M. S. (2006). Metode Penelitian. Kuantitatif Kualitatif.

Sedarmayanti, M., \& Pd, M. (2001). Sumber daya manusia dan produktivitas kerja. Bandung: CV. Mandar Maju.

Shim, K. R., Paek, B. J., Yi, H. T., \& Huh, J. H. (2017). Relationships between golf range users' participation motivation, satisfaction, and exercise adherence intention. Asia Pacific Journal of Innovation and Entrepreneurship, 11(1), 50-62.

Simamora, H. (2004). Manajemen sumber daya manusia.

Sugiyono, P. Dr. 2014. Metode Penelitian Kuantitatif, Kualitatif, dan R\&D. Bandung: CV Alfabeta.

Suliyanto, D. (2011). Ekonometrika Terapan: Teori dan Aplikasi dengan SPSS. Penerbit Andi: Yogyakarta. 
Sumarno, E., Pradhanawati, A., \& Farida, N. (2013). Pengaruh Kompensasi dan Motivasi Terhadap Produktivitas Kerja Melalui Kepuasan Kerja Sebagai Variabel Intervening (Studi Kasus pada Karyawan Bagian Produksi PT. Estika Pulau Mas Tegal). Jurnal Ilmu Administrasi Bisnis, 2(3), 131-137.

Trihendardi, C. (2004). Memecahkan Kasus Deskriptif, Parametrik dan Nonparametrik dengan SPSS 13. Andy, Yogyakarta.

Uno, H. B. (2008). Teori motivasi dan pengukurannya. Jakarta: Bumi Aksara.

Yuliannisa, S. N., Basrindu, G., \& Yani, A. (2017:95). Pengaruh Kompensasi Dan Motivasi Terhadap Produktivitas Kerja Di Pt Inter Pan Pasifik Futures Banjarmasin. Administraus, 2(1), 93-106.

Zainal, V. R. dkk. 2014. Manajemen Sumber Daya Manusia Untuk Perusahaan Dari Teori Ke Praktik, PT Rajagrafindo Persada: Depok. 